Geopolítica(s) Revista de estudios sobre espacio y poder ISSN: 2172-3958

\title{
Estados y espacios de excepción en una zona de frontera del Caribe colombiano
}

\author{
Carlos Arturo Salamanca Villamizar²
}

Recibido: 22 de febrero de 2016 / Aceptado: 24 de junio de 2016

Resumen. Los indígenas wayúu, habitantes de la península de La Guajira en la frontera colombovenezolana, en las últimas dos décadas han enfrentado graves situaciones de violencia y el avance de empresas mineras extractivas en sus territorios. En años más recientes, han enfrentado también una grave crisis humanitaria a causa de la falta de acceso al agua potable y la alimentación. En este trabajo postulo que las nociones de Estado de excepción y excepcionalidad son pertinentes para analizar los dispositivos de poder en las zonas de frontera y las condiciones en las cuales la vida individual y colectiva son (o no) posibles. Posteriormente, analizo los vínculos entre las alteridades y los dispositivos de poder evidenciando las articulaciones entre neoliberalismo y multiculturalismo. En la última parte argumento porqué una perspectiva espacial habilita un posicionamiento que puede esbozar algunas respuestas frente a los estados de excepción en los que la vida misma es incierta.

Palabras clave: wayúu; colonialismo; zonas de frontera; estados de Emergencia; política de identidad.

\section{[en] States and Spaces of Exception in a Colombian Caribbean Borderland}

\begin{abstract}
The Wayúu indigenous peoples inhabit the Guajira Peninsula on the ColombianVenezuelan border. In the last two decades, they have suffered severe situations of violence and the advancement of mining in their traditional territory by transnational companies. In recent years, the Wayúu also live a severe humanitarian crisis due to lack of access to drinking water and food. In this paper I affirm that the notions of state of emergency and exceptionality are relevant to analyze power apparatus in the borderlands and the conditions under which individual and collective life are (or not) possible. Second, I analyze the links between otherness and power apparatus showing the links between neoliberalism and multiculturalism. Finally, I argument why a spatial perspective enables a positioning that can outline some responses to states of emergency in which life itself is uncertain.
\end{abstract}

Keywords: Wayúu; colonialism; borderlands; state of emergency; politics of identity.

1 Una version preliminar de este trabajo fue presentada bajo el título: "Espaces d'exception : Identités, altérités et dispositifs de pouvoir dans une zone de frontière dans le Caraïbe colombien" en la mesa Territoires, violences et ségrégation del III Colloque International La ségrégation à l'ordre du jour, París, diciembre 2015 coordinado por Elise Pestre, Carlos Salamanca y Perla Zelmanovich. Agradezco a los colegas y participantes del encuentro cuyas preguntas y observaciones contribuyeron a enriquecer el argumento.

2 Arquitecto. Doctor en Antropología e Investigador de CONICET/UNR.

E-mail: salamanca.carlos@gmail.com 


\section{[pt] Estados e espaços de exceção numa zona de fronteira do Caribe colombiano}

Resumo. Os indígenas wayúu, habitantes da Península de La Guajira na fronteira venezuelana, nas
últimas duas décadas têm enfrentado situações graves de violência e o avanço das mineradoras
extrativas em seus territórios. Em anos mais recentes, têm enfrentado também uma grave crise
humanitária devido à falta de acesso para a água de beber e os alimentos. Neste trabalho afirmo que
as noções de estado de exceção e excecionalidade são relevantes para analisar os dispositivos de
poder nas áreas de fronteira e as condições em que a vida individual e coletiva são (ou não) possíveis.
Posteriormente, analiso as ligações entre as alteridades e os dispositivos de poder, demonstrando as
articulações entre o liberalismo e o multiculturalismo. Na última parte argumento que uma perspetiva
espacial permite um posicionamento que pode delinear algumas respostas aos Estados de emergência,
nos quais a vida em si é incerta. Palavras-chave: wayúu; colonialismo; zonas de fronteira; estados de emergência; política de identidade.

Sumario. Presentación. 1. Fronteras, Estados y espacios de excepción. 1.1. Zonas de frontera y dispositivos de poder. 1.2. Experiencia coloniales y estados de excepción. 2. Estado de excepción y excepcionalidad. 2.1. La escala nacional. 2.2. La escala regional. 2.3. La Guajira: nodo y espacio de la excepción y la excepcionalidad. 3. Nuda vida y nuda muerte: alteridades y dispositivos de poder en La Guajira. 3.1. Neoliberalismo y multiculturalismo: una eficaz articulación. 3.2. La sed en La Guajira contemporánea: ¿una paradoja? 4. Interrogantes en torno a lo transversal y lo común. Comentarios finales. Bibliografía.

Cómo citar: Salamanca Villamizar, Carlos Arturo (2016) "Estados y espacios de excepción en una zona de frontera del Caribe colombiano". Geopolítica(s). Revista de estudios sobre espacio y poder, vol. 7, núm. 2, 227-250.

\section{Presentación}

Unas 150.000 personas que se reconocen actualmente como wayúu, habitan en conjuntos familiares de vivienda rural y barrios periurbanos distribuidos en unos 15.000 kilómetros cuadrados en la península de La Guajira, a orillas del mar Caribe, y a ambos lados de la frontera colombo-venezolana ${ }^{3}$. En esta región coexisten un modelo político, económico y cultural basado en el extractivismo y un orden paradójico, inestable e incierto que resulta de las contradicciones y tensiones entre varios modelos político-económicos incompletos entre los que sobresalen dos: uno republicano de raíz liberal de raigambre universalista y otro multicultural, más reciente, centrado en el reconocimiento político de los Pueblos Indígenas como sujetos jurídicos colectivos sobre la base de su condición de grupos particulares de población que adscriben a un conjunto de valores, principios y visiones del mundo. A su vez, esta zona está marcada por experiencias individuales y colectivas de violencias antiguas y recientes, ejercidas por múltiples actores tanto legales como ilegales y que persisten en diversas esferas de la vida social. Finalmente, la Guajira está atravesada por tráficos legales e ilegales de bienes, sustancias y personas en si-

3 Los wayúu son uno de los 81 grupos étnicos que actualmente existen en Colombia. A él pertenecen aproximadamente 148.000 de los 700.000 indígenas oficialmente reconocidos, representando así uno de los pueblos más numerosos en el país, mientras que en Venezuela representan el 57,3\% de la población indígena nacional. Este trabajo se centra en la experiencia de los wayúu en territorio colombiano. 
tuaciones de frontera en una economía de transacciones, situaciones de legalidad e ilegalidad.

Un modelo económico basado en el extractivismo y la explotación a gran escala de los recursos naturales, la coexistencia de dos modelos políticos incompletos y contradictorios, la persistencia de la violencia, los tráficos y transacciones de frontera, y una sociedad marcada por los recuerdos y los traumas de la violencia, son los elementos que conforman el cuadro a partir del cual pueden dibujarse algunas de las características de la gubernamentalidad en las zonas de frontera, siendo las nociones de excepción y de excepcionalidad constituyentes de dichas características.

Este trabajo tuvo su inicio por una aparente paradoja. En los últimos años, mientras la cultura wayúu tiene una visibilidad pública cada vez mayor, se celebran dos décadas de crecimiento económico sostenido y exponencial, se habla del fin del conflicto en Colombia y se despliega la justicia transicional, en los últimos años miles de niños wayúu vienen muriendo de sed y de hambre en La Guajira.

En la primera parte analizo la especificidad de las zonas de frontera y explico por qué nociones como las de estado de excepción y excepcionalidad son útiles para su análisis. Posteriormente, abordo el proceso de constitución histórica de $\mathrm{La}$ Guajira como un nodo de articulación de dispositivos de poder de distintas escalas en los que se despliegan los principios de la excepción y la excepcionalidad. En la tercera parte analizo los vínculos entre las alteridades y dichos dispositivos evidenciando las articulaciones entre neoliberalismo y multiculturalismo, y discutiendo el carácter paradójico de las mencionadas muertes por desnutrición. Concluyo refiriéndome a los nuevos escenarios de acción política en los que emerge la pregunta por lo común, y afirmo que los posicionamientos territorializados esbozan algunas respuestas frente a los estados de excepción e incertidumbre.

Este trabajo ha sido elaborado a partir de la revisión de la bibliografía especializada sobre la región y sobre los wayúu, artículos de prensa y fuentes secundarias. Esta revisión fue realizada teniendo como base y sustento el trabajo de campo realizado para una investigación comparativa aun en curso ${ }^{4}$.

\section{Fronteras, Estados y espacios de excepción}

\subsection{Zonas de frontera y dispositivos de poder}

Las zonas de frontera son un nodo denso de articulación de mecanismos disciplinarios y de despliegue de prácticas que intervienen entre los seres humanos y el medio. Al igual que otras zonas de frontera latinoamericanas, La Guajira tradicionalmente ha sido vista como un territorio salvaje, un desierto hostil, un "territorio otro" al margen de la legalidad. Esta concepción, simultáneamente social y territo-

$4 \quad$ El trabajo de campo ha sido realizado en dos etapas. La primera entre abril y mayo del 2015 y la segunda en los mismos meses del año 2016. Por las dinámicas mismas analizadas, el trabajo de campo incluye tanto entrevistas y observación participante realizada en distintos asentamientos indígenas de la región, como el trabajo de revisión documental realizado en bibliotecas y archivos en Riohacha y La Guajira. El proyecto comparativo "Espacios de violencia, sitios de memoria y lugares de elocución: espacio y mediación en la política indígena contemporánea latinoamericana" lo desarrollo gracias al apoyo de CONICET. 
rial, habla de dos figuras enfrentadas una a la otra por oposiciones como civilizado/no civilizado, tradicional/moderno, conquistado/salvaje, y un mismo isomorfismo. Por una parte, el del territorio, identidad y cultura de las "poblaciones otras" a quienes se les atribuye una identidad original, coherente, cerrada, claramente delimitada y ahistórica (Gupta y Ferguson, 2008 [1997]). Por otra, el de la Nación como un sistema articulado de territorio, población y sistema administrativo, instituido de una vez y para siempre. Estas dos figuras vienen siendo cuestionadas a través de investigaciones que proponen perspectivas procesuales y aproximaciones distintas a las dicotómicas (entre otros Agier, 2015; Anderson, 1993 [1983]; Bhabha, 1994; Malkki, 1995; Parekh, 1995; para trabajos sobre Colombia ver: Steiner, 2000; Madariaga, 2006; Aparicio, 2012; Serje, 2011[2005]).

Das y Poole (2008) y Asad (2008) propusieron analizar las formas del poder y el derecho estatal en los márgenes, lejos del "centro", frente a su inestabilidad en territorios no incorporados, en espacios inacabados y en los intersticios. La concepción del poder como algo procesual y no definitivo está vinculada con un pensamiento que intenta superar las perspectivas con que tradicionalmente ha sido conceptualizado el Estado y las zonas de frontera mismas.

Proponiéndose superar las dicotomías "que estructuran la cultura", escapar a las "escisiones que las han producido" y transformar las dicotomías en polaridades, Giorgio Agamben propuso "una lógica del campo, más que de la sustancia" (2010 [2003]: 12) y ubicó al sujeto en un campo recorrido por la tensión entre tendencias opuestas "una que va hacia la subjetivación, y otra que procede en la dirección opuesta" (2010 [2003]: 17). Retomando del derecho romano arcaico la figura del homo sacer, Agamben aborda la "bio-política contemporánea" (2010 [2003]: 13) con el fin de acceder al núcleo problemático de la relación entre anomia y derecho, estructura constitutiva del orden jurídico; en este contexto, la nuda vida emerge en tanto producción específica del poder y no como un dato natural (2010 [2003]: 18).

Los aportes de Agamben se articulan con las contribuciones de Foucault (2004 [2001]; 2000 [1997]: 222) acerca del cambio en los dispositivos de poder frente a la emergencia de la población como problema bio-político, un fenómeno colectivo que se desarrolla en el tiempo. Se trata de campos de intervención de la biopolítica en los que los dispositivos emergen como técnicas del bio-poder: intervenciones ligadas a eventos como el nacimiento, la muerte, la enfermedad y los ámbitos de relación de los seres humanos como seres vivientes y su medio de existencia.

Confrontados por las nuevas formas de gobierno desencadenadas por los acontecimientos del 11 de septiembre 2001, Agamben (2010 [2003]), Hardt y Negri (2004) y otros autores (ver más adelante), retomaron y reformularon la figura del "estado de excepción" propuesta en su forma clásica por Carl Schmitt. Para Agamben, se trata de una medida excepcional fruto de un periodo de crisis política, un dispositivo que desdibuja los supuestos límites entre política y derecho, y se presenta como "la forma legal de algo que no puede tener forma legal", una suspensión del orden que "abandona lo viviente en manos del derecho" y estableciendo "una tierra de nadie" entre "el derecho público y el hecho político, entre el orden jurídico y la vida" (Agamben, 2010 [2003]: 24).

Retomando los aportes de los promotores del llamado "giro espacial" (Foucault 1984[1967]; Warf y Arias, 2014; Soja, 1996), varios autores retomaron la cuestión (Gregory, 2006; Arteaga, 2009; Hannah, 2008). Entre ellos, Reid-Henry (2007) 
abordó las modalidades y las formas de los estados de excepción, analizando, primero, las varias modalidades geográficas de estados particulares de excepción al interior de los cuales cobran forma los poderes (en plural). Segundo, las lógicas geográficas que modelan el despliegue del poder y sus entrelazamientos coconstitutivos con los espacios de excepción. Tercero, los espacios de excepción desde una perspectiva histórico-geográfica que vincula los elementos del pasado con los escenarios posibles de futuro.

\subsection{Experiencia coloniales y estados de excepción}

En los últimos años un gran número de investigaciones han venido replanteando la idea del colonialismo, reconociéndolo como un vínculo relacional co-constituyente entre las metrópolis y las colonias. Entre el amplio universo de trabajos, destacamos aquellos que, elaborados desde una perspectiva espacial, se han detenido en prácticas como la zonificación, la razzia, la tierra quemada, el desplazamiento forzoso, la segregación territorial y el campo como figura de tratamiento bio-político (Lal, 2005; Njoh, 2008; Stanard, 2009). En esta misma línea, Jameson (2003: 700), cuestionó la separacion epistemológica entre las metrópolis y las colonias, así como el sistemático ocultamiento de la explotación colonial en la prosperidad imperial. Mientras que, para Mbembe, la propia estructura del sistema de plantación, característico del colonialismo, y sus consecuencias traducen en ciertos aspectos "la figura emblemática y paradójica del estado de excepción" (2011: 31). En el planteamiento de Mbembe acerca de la triple pérdida que atraviesa el esclavo en la plantación subyace una importante dimensión espacial. Alienado del hogar, dominado absolutamente en su cuerpo, expulsado de la esfera de lo humano, es en la plantación en donde el esclavo pertenece al amo.

A diferencia de esta tendencia, en su ya clásica formulación, Agamben reconoció las experiencias históricas en Europa del siglo XX, como el laboratorio en el que "los mecanismos y dispositivos del Estado de Excepción como paradigma de gobierno fueron experimentados y puestos a funcionar" (2010 [2003]: 33). Ninguna referencia a las experiencias coloniales.

Por otra parte, Svirsky y Bignall (2012: 7) introdujeron la idea de estados coloniales de excepción y propusieron abordar "el encuentro colonial" como una dimensión formativa de los "paradigmas occidentales" retomados por Agamben, en la línea de análisis propuesta por Arendt (2006) al vincular totalitarismo y colonialismo. Entre éstos, sobresalen dos cuestionamientos a Agamben: el ignorar el rol del imperialismo al conceptualizar la noción de soberanía en Europa (Shenhav, 2012: 8), y el pasar por alto el hecho que para los colonizados, la soberanía colonial significó un estado de excepción permanente (Morton, 2012: 9). En sus cuestionamientos Gregory $(2004,2006)$ reprochaba a Agamben sus "limitaciones" para reconocer la continuidad los "espacios de excepción y las arquitecturas del poder colonial", por no prestar atención suficiente a las espacialidades del derecho internacional", y por cierto pesimismo frente a las "políticas de la resistencia".

Aunque también propuso un paralelismo e identificó continuidades entre colonias y fronteras (2011) Mbembe soslayó el debate acerca de si las experiencias totalitarias europeas tienen su origen en la colonia o si son la continuidad de mecanismos y formaciones sociales y políticas de Europa Occidental. Lo que importa, 
afirma, es que "la colonia representa el lugar en el que la soberanía consiste fundamentalmente en el ejercicio de un poder al margen de la ley ( $a b$ legibus solutus) y donde la "paz" suele tener el rostro de una "guerra sin fin" (2011:37).

Abordar la idea de excepcionalidad en las zonas de frontera requiere una doble indagación en torno a la forma en que los Estados latinoamericanos hicieron uso de los paradigmas europeos del Estado de Excepción como forma de ejercicio del poder en el marco de las soberanías, y del paradigma europeo de la excepcionalidad en el contexto colonial como forma de ejercicio del poder en las zonas de frontera. En América Latina, el tema ha sido abordado por diversos autores entre los que citamos a González Jacome (2007: 35) quien subrayó la necesidad de estudiar no sólo los procesos de formación de las naciones latinoamericanas sino el orden social colonial que les precedió argumentando que el fin del régimen colonial no implicó el fin de las dinámicas coloniales. ¿Cuál es el significado bio-político del estado de excepción así planteado? ¿De qué naturaleza son aquellos territorios en los que el estado de excepción no es un medio a través del cual se instauran prácticas totalitarias excepcionales sino el elemento constituyente de la sociedad y de la cultura?, ¿Cómo pensar aquellos territorios en los que se permite la eliminación física de los adversarios, el dejar morir de los ajenos? Antes de abordar estos interrogantes, me referiré brevemente al proceso histórico de constitución del estado de excepción y de la excepcionalidad en La Guajira, centrándome en las formas en que la zona de frontera se constituyó como un espacio relacional.

\section{Estado de excepción y excepcionalidad}

Para los wayúu y otros habitantes de La Guajira el estado de excepción y la excepcionalidad se manifiestan y despliegan como el resultado de múltiples articulaciones espaciales y temporales. En la práctica, lo local, lo nacional, lo global —al igual que el pasado, el presente y el futuro - no operan de manera autónoma; no obstante, para efectos meramente explicativos, me referiré separadamente a la escala nacional y posteriormente a la regional ${ }^{5}$. En la línea de lo propuesto por autores como Radcliffe (2007), Sassen (2010 [2006]) o Comaroff y Comaroff (2003), desde una perspectiva espacial, intentaré integrar analíticamente las escalas, identificar sus puntos de articulación y develar las múltiples dinámicas de construcción de identidades deteniéndome en las negociaciones, con frecuencia violentas, de sus significados y prácticas. El movimiento permanente entre distintas escalas parece doblemente necesario frente a la necesidad de evitar la "disolución de las particularidades locales en la monotonía uniforme de las condiciones globales, sin tratar la distinción radical de lo local como si estuviera enfrentado o apartado de lo global" (Foster, 2002, en Comaroff y Comaroff, 2003: 271, mi traducción).

\subsection{La escala nacional}

Si, como afirman varios autores (Uribe de Hincapié, 1999, 2001; Palacios, 1995; Pécaut, 1987; González et al., 2003), la violencia ha sido la médula espinal de la

\footnotetext{
${ }^{5}$ Análisis a escala global y local también serían necesarios pero los mismos superan los alcances de este artículo.
} 
historia institucional colombiana, la excepción ha sido a su vez, su principal argumento. Desde finales del siglo XIX el Estado colombiano recurrió reiteradamente al estado de sitio (Artículo 121 de la Constitución Política de 1889), con una mayor intensidad en las décadas de 1950 y 1960 para todo tipo de acciones y, al menos hasta 1974 "los estados de excepción acabaron por convertirse en permanentes" (CNMH, 2013: 129). Entre 1949 y 1991 Colombia vivió más de 30 años bajo estado de sitio y entre 1978 y 1985 la represión, como afirma González Jacome (2007) fue la forma en que se lidió con el disenso político. Instrumentos legales sancionados en 1978, 1988, 1990, 1992, 1994, 1995, 2002, de una u otra forma apelaban al estado de sitio, a la noción de excepcionalidad, y al recorte de las garantías constitucionales frente a situaciones interpretadas como de amenaza o riesgo para la seguridad y estabilidad de "la Nación". No obstante, mientras más crecía el aparato represivo de la mano de la utilización de la figura de la excepcionalidad, más se incrementaba el delito y el conflicto que el mismo aparato quería resolver (García Villegas, 2008), creando las condiciones para la declaratoria de nuevos Estados de Excepción. En referencia a diferentes regiones de Colombia se ha descrito cómo en este contexto surgieron "regímenes de autoridad territorial" (Agnew y Oslender, 2010: 194), "territorialidades bélicas" (Uribe de Hincapié, 1999: 25), así como soberanías en conflicto o en disputa (Agnew y Oslender, 2010), en tensión o superpuestas (Uribe de Hincapié, 1999; Mason, 2005; Safford y Palacios, 2002).

Aun con diferentes niveles de intensidad de acuerdo al contexto histórico y político, el recurso recurrente a la excepcionalidad en Colombia, dio lugar a tres particularidades: el involucramiento de los civiles en los conflictos y confrontaciones armadas, el ejercicio de la violencia por parte de actores privados que actuaban por "alianzas funcionales y coyunturales entre sectores económicos, políticos y militares" (CNMH, 2013: 140) y la sobrevaloración de la participación de la Fuerza Pública en la dinámica institucional del Estado con el consecuente desequilibrio del balance constitucional entre las ramas del poder público (García Villegas, 2008; Uribe de Hincapié, 1999; García y Uprimny, 2006). En síntesis, la excepcionalidad fue un elemento constitutivo de las relaciones entre violencia y derecho a lo largo de toda la historia institucional colombiana, siendo una de sus más claras manifestaciones en el pasado reciente el surgimiento y expansión del paramilitarismo.

Desde mediados de la década de los años 1990 y al menos hasta su desmovilización oficial en el año 2005, organizaciones armadas privadas e ilegales conocidas en su conjunto como el fenómeno del "paramilitarismo" se expandieron por todo el país de manera articulada a sectores de las Fuerzas Militares y de amplios sectores de la sociedad. Su origen, al menos en términos retóricos, estuvo ligado a una "situación excepcional de emergencia": la defensa contra los movimientos guerrilleros y algunas de sus acciones en contra de terratenientes, comerciantes, políticos y narcotraficantes. A mediados de la década de los 1990, los paramilitares, en alianza con políticos, empresarios y militares, se propusieron la construcción de un verdadero nuevo orden político, jurídico y económico, un nuevo contrato social $(\mathrm{CNMH}$, 2013: 160), a través de la violencia. Su expansión se vio favorecida por la guerra global contra el terror en cuyo marco, desde el 2001, se reprodujeron de variadas formas los principios de excepción y de excepcionalidad, ofreciendo un conjunto de premisas, conceptos, prácticas y legitimidades entre los que sobresale la figura del terrorista a través de la cual fueron clasificados y tratados los "enemigos inter- 
nos", instrumentalizando la lógica de la excepción (Agamben, 2010 [2003]). Haciendo uso de esta categoría flexible, el Estado recurrió a los paramilitares para perseguir, amedrentar y eliminar a campesinos, periodistas, sindicalistas, entre otros, impulsando una guerra del terror que a nivel nacional, desdibujó los límites entre legalidad e ilegalidad, Estado y estructuras políticas paralelas, propósitos colectivos e intereses privados.

Esas violencias privilegiaron a los indígenas y otras poblaciones de zonas de frontera como La Guajira configurando estados no excepcionales de excepción en los que se instituyó la impunidad, víctimas se confundieron con victimarios, y a través de la violencia a gran escala se sentaron las bases para la construcción de un nuevo orden moral, político y económico. Para finalizar, señalemos que, después de su desmovilización oficial, las estructuras paramilitares se reconfiguraron en una decena de nuevas organizaciones con presencia en casi todo el país bajo diferentes denominaciones (ONU, 2015). En La Guajira estas bandas se dedican a actividades como el control y tráfico de estupefacientes y el contrabando de gasolina, haciendo uso de la violencia tanto en contra de la población civil como entre ellas mismas por el control de dichos territorios.

\subsection{La escala regional}

En La Guajira la noción de excepcionalidad y de excepción tuvo su propio proceso. A diferencia de la imagen bucólica más habitual de pueblos autóctonos, aislados, prístinos y separados de toda interacción con el mundo colonial, desde inicios del siglo XVI los indígenas wayúu de La Guajira interactuaron intensamente con los actores coloniales (autoridades, misioneros, comerciantes y piratas) primero, y republicanos de Colombia y Venezuela posteriormente. Esta interacción fue intensa pero no generalizada, en el sentido que no fue el resultado de una colonización definitiva y a gran escala sino de relacionamientos situados y episódicos. En virtud de la localización geográfica de la península en el epicentro de los circuitos comerciales del Caribe en la época de la Colonia, y en una situación liminar con respecto a las repúblicas de Colombia y Venezuela, esta interacción se dio principalmente a través del comercio. Las relaciones comerciales de los wayúu reconfiguraron la geografía regional dando lugar a una geografía compuesta por puertos y caminos que, por las características desérticas del terreno especialmente en la Media y Alta Guajira, eran utilizados casi exclusivamente por los wayúu. En un territorio atravesado por una frontera nacional más declarada que efectiva, el comercio regional en su mayoría fue de contrabando y en él participaron indígenas, extranjeros, colonos y las autoridades mismas con niveles similares de intensidad al menos hasta el inicio del siglo XX (Polo Acuña, 2012: 119; Serje, 2011 [2005]: 275). En este contexto, los wayúu pudieron mantener, al menos hasta mediados del siglo XX, autonomía política y un control territorial relativamente efectivo.

Además de su reputación como avezados comerciantes, durante los siglos XVI y XVII los wayúu se granjearon la reputación de aguerridos y hostiles debido a episodios puntales de ataques y hostilidades como los sucedidos en 1724, 1769, 1775, y otros de mayor escala como la "rebelión guajira" (1769), y que se exten-dieron al menos hasta la guerra por el control de los territorios en la zona sur de La Guajira entre 1830 y 1850 (Polo Acuña, 2012: 275). Desde la fundación de las primeras 
poblaciones a finales del siglo XVI, dichas hostilidades se produjeron por el acceso al agua, los abusos de colonos y autoridades en contra los indígenas en la pesquería de perlas, y la negativa de los indígenas al acceso de los misioneros que, de manera articulada al sometimiento por las armas, era impulsada en la zona desde finales del siglo XVII (Polo Acuña, 2012: 134). Para sintetizar, las políticas de pa-cificación de La Guajira consistieron en tres estrategias articuladas y yuxtapuestas: la evangelización, la persuasión y la represión armada (Polo Acuña, 2000).

Apoyándome en los datos de la investigación de Polo Acuña (2012), enumero situaciones que dieron lugar a modalidades excepcionales de conquista, evangelización, comercio y sometimiento durante el siglo XVIII. Holanda e Inglaterra se aprovecharon de la situación contradictoria de La Guajira que como todas las otras zonas de frontera, era un territorio bajo el poder soberano pero abandonado por el Imperio Español, el contrabando era una actividad ilícita pero al menos desde el siglo XVIII contaba con tal legitimidad que durante décadas Santa Marta y Riohacha se abastecían principalmente a través del contrabando, los nativos estaban en territorio español pero firmaban tratados de cooperación y protección con empresarios y autoridades de Curasao y Jamaica, los nativos solían mantener relaciones de hostilidad con los criollos pero excepcionalmente eran intermediarios en el contrabando que aquellos mantenían con compradores de las Antillas y Riohacha, el interés en el sometimiento de los indígenas de la Corona española se ajustaba a intereses particulares de autoridades, funcionaros reales y militares, los misioneros se propusieron la transformación de los indígenas en agrícolas sedentarios pero ese proyecto se mostró inviable por la aridez del territorio, los nativos participaron en las gestas de independencia pero a ambos lados y en función de sus intereses y las relaciones personales que mantenían con autoridades y militares.

Durante la primera mitad del siglo XIX los gobiernos de Colombia y Venezuela tuvieron como política el obsequiar a los indígenas con el objeto de "atraerlos a la vida civilizada" (Polo Acuña 2012: 282); además de aguardiente, tabaco y panela, la práctica se llegó a institucionalizar a través de tierras, herramientas y ganado (Polo Acuña, 2012: 297). La segunda mitad del siglo XIX se caracterizó por el despliegue (parcial) de dispositivos de poder tanto desde Colombia como desde Venezuela como la expansión y la ocupación militar, la fundación de poblados y el impulso al comercio controlado y regulado con el propósito de nacionalizar dichos territorios y a sus habitantes (Polo Acuña 2012: 282). En ese marco y con un mismo proyecto, se fundan a lo largo del siglo XX Maicao (1927), Uribia (1935) y Manaure (Polo Acuña, 2012: 173).

Desde la década de los años 1960 y 1970, la frontera de La Guajira fue además el canal de redes de tráfico de marihuana y gasolina desde Venezuela. A partir de la década de los años 1980 armas y cocaína se sumarían a las mercancías que circulaban en la región. En todas estas formas de tráfico la participación de los wayúu existió aunque ésta fue minoritaria con excepción del contrabando y la gasolina en donde sí tuvieron preponderancia. El Estado, ausente o cómplice, se vio siempre limitado frente a estos tráficos y a la violencia que les estaba asociada, principalmente la ejercida por los paramilitares, con quienes el ejército siempre mantuvo una relación ambigua. Una región por fuera del control del Estado, un desierto impenetrable, un territorio de violencia, una zona árida y hostil y una provincia alterizada de la mano de la alterización de sus habitantes: tales fueron los imaginarios 
que marcaron La Guajira como un territorio de excepción. Una vez presentados a grandes rasgos los procesos históricos de constitución a nivel nacional y a nivel local, veamos cómo se articulan en el contexto actual y regional.

\subsection{La Guajira: nodo y espacio de la excepción y la excepcionalidad}

A finales de la década de los años 1990, para narcotraficantes, contrabandistas y paramilitares las redes y nodos que los wayúu construyeron a lo largo de varios siglos de intercambios comerciales se convirtieron en un escenario estratégico para el despliegue de sus propias redes de tráfico. La conquista de dichas redes y nodos fue el motivo de asesinatos, masacres y una violencia sin precedentes. En esta zona de frontera la guerra contra el terror y la guerra contra los terroristas derivada de las versiones vernáculas de la Guerra Fría se articularon con los tropos coloniales de la alteridad, en disputas que eran principalmente territoriales. A nivel nacional, esa articulación, sumada a la superposición de las geografías indígenas y de las geografías de los recursos naturales (Aparicio, 2012: 23) generó una inusitada violencia contra los indígenas (Villa, 2004; García Hierro y Jaramillo, 2008). Al igual que en otras regiones, en La Guajira, la violencia perpetrada por los paramilitares, se "adaptó culturalmente" para afectar aún más a los wayúu (CNMH, 2010; Ochoa Sierra, 2011). Asimismo, varias masacres y asesinatos contra los wayúu fueron cometidos con la participación o la permisibilidad de un Estado que en varias ocasiones intentó justificar o matizar la gravedad de la violencia presentándola como una supuesta costumbre cultural (CNMH, 2010).

En La Guajira estamos frente a un orden en el que el que no sólo el monopolio de la fuerza del Estado ha estado desde su origen desdibujado y en el que la violencia ha tenido un rol constituyente. Resultado de articulaciones contingentes, este nuevo orden en emergencia incluye estructuras delicuenciales pequeñas y flexibles, organizaciones de contrabando, carteles de droga, oficinas del Estado, que coexisten y se articulan de maneras complejas y circunstanciales. En este caso, no estamos frente a regímenes democráticos que en respuesta a ciertos acontecimientos adoptan el estado de excepción. Más bien, la excepcionalidad fue un elemento constitutivo en un conjunto de relaciones entre estructuras que despliegan sus propias formas de soberanía, con frecuencia en disputa (Agnew y Oslender, 2010: 193) que coexisten con diversos tipos de áreas de excepción. Como resultado de estas territorialidades superpuestas la autoridad territorial del Estado se ve cuestionada por la "formación de nuevos tipos de autoridad" (Mason, 2005: 50).

Se trata de territorios en los que las cancelaciones del estatuto jurídico hacia determinados individuos no provienen solo de medidas legales o administrativas ni provienen exclusivamente del Estado. En aquellos espacios situados por fuera o más allá del orden jurídico y político, dichas cancelaciones en ocasiones son de hecho y son promovidas tanto por el Estado como por otros actores (aunque articulados a él). Es así que de acuerdo a las circunstancias, el ejército, la guerrilla, los paramilitares, los contrabandistas o los narcotraficantes suspenden el orden jurídicopolítico del Estado de derecho en zonas, barrios y territorios a veces de manera autónoma (y en disputa), y a veces de manera articulada (y consensuada). En tanto paradigma de gobierno el Estado de excepción en el centro se relaciona de múltiples formas con el paradigma de las excepcionalidades en la periferia. 
Una vez descrita la articulación del proceso de constitución del Estado de excepción y de excepcionalidad a distintas escalas, retomo las preguntas esbozadas al inicio acerca de las implicancias en las zonas de frontera de las nociones de excepcionalidad. En la siguiente parte, haré referencia a la expansión de economías extractivas en la región y el surgimiento de los wayúu como sujetos de derecho. Aunque cada una de estas dinámicas sea de gran complejidad, requieran de un análisis propio y hagan parte en principio, de procesos separados, quiero subrayar que, en la práctica, están estrechamente articuladas.

\section{Nuda vida y nuda muerte: alteridades y dispositivos de poder en La Guajira}

\subsection{Neoliberalismo y multiculturalismo: una eficaz articulación}

La creación de la mina de carbón a cielo abierto de El Cerrejón en la primera mitad de la década de 1980 en la cuenca del río Ranchería, al sureste de La Guajira, produjo una transformación a gran escala, tanto en términos físicos (por la dimensión de su infraestructura), como en términos económicos (por el volumen del dinero entregado en concepto de impuestos) ${ }^{6}$. La mina significó también el surgimiento de nuevos órdenes políticos y económicos, al constituirse como el inicio de una gran expansión de proyectos promovidos por empresas transnacionales de explotación minera (gas, petróleo, carbón) ${ }^{7}$. Ver Mapa 1 . Al igual que El Cerrejón que en la actualidad cuenta con un área de 69.000 hectáreas (Roa Avendaño y Navas, 2014), estos emprendimientos afectan directa y profundamente a los wayúu así como a los demás habitantes de La Guajira con intensidades que varían de acuerdo a su localización (Puerta Silva y Dover, 2008; Puerta Silva 2014). Asimismo, como señalan Urrea y Rodríguez Maldonado (2014: 82), El Cerrejón tiene en la actualidad cinco fundaciones con gran incidencia en los planes de ordenamiento territorial, de conservación ambiental y en la construcción en general de las políticas públicas del departamento, suplantando en ocasiones al mismo Estado.

Cada uno de estos emprendimientos constituye enclaves, áreas y zonas cercados por muros, mallas, fronteras visibles e invisibles y legislaciones y normativas propias, al interior de las cuales operan reglamentaciones específicas, aunque diversas en sus escalas y configuraciones espaciales. Entre éstos, dos lugares emblemáticos merecen ser mencionados. Por una parte, la unidad residencial Mushaisa, un complejo de habitación destinado a los empleados de El Cerrejón. Cerrado y con vigilancia del ejército y de una empresa de seguridad privada, el conjunto incluye 297 casas, 430 apartamentos y un hotel para alojamiento de más de 200 personas de

6 La mina es explotada actualmente por las compañías multinacionales BHP Billiton (Australia), Anglo American (Sudáfrica) y Glencore (Suiza), y produce en la actualidad 32,8 millones de toneladas de carbón al año, con utilidades que representan casi un punto porcentual del PIB colombiano y más de la mitad del PIB del departamento.

7 Además de la ampliación de la mina de El Cerrejón hay previstos diversos proyectos como la explotación de la plataforma gasífera y petrolera Bloque Tayrona, el Puerto Multipropósito de la empresa Brisa, la construcción del gasoducto transcaribeño, y el desembarco de empresas de turismo internacional, que se suman a proyectos ya realizados como el parque eólico Jepirachi y diversos proyectos de conservación, ubicados en el territorio wayúu o en sus proximidades. 
habitaciones con aire acondicionado, locales comerciales, restaurantes, piscina, un colegio bilingüe y otros servicios destinados a más de 2.200 residentes.

Mapa 1. La Guajira, el territorio wayúu y los proyectos minero-energéticos

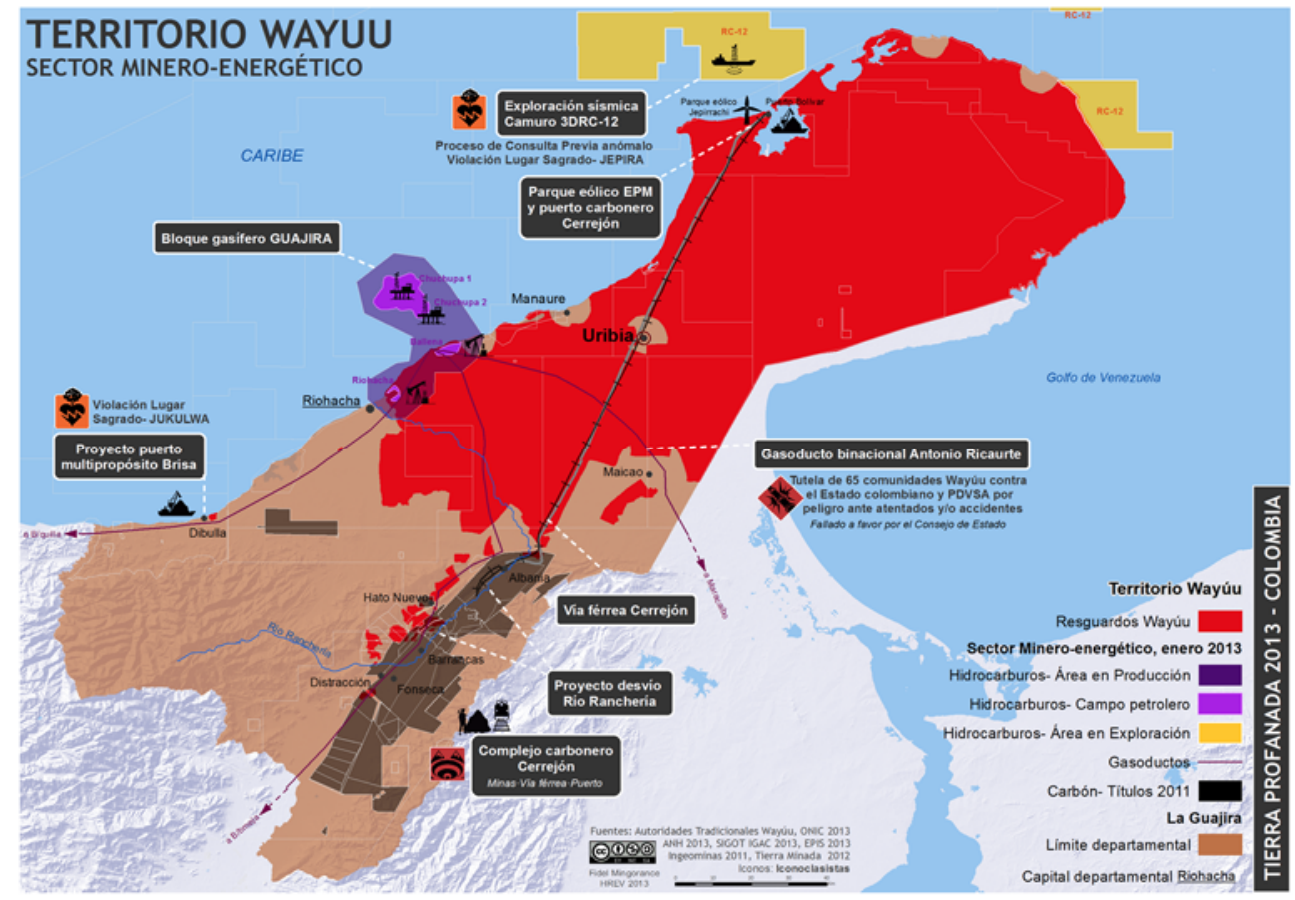

Fuente: URL: <http://www.geoactivismo.org > Consultado el 26 de enero de 2013.

Por otra, el ferrocarril de $150 \mathrm{~km}$ que une la mina de El Cerrejón con Puerto Bolívar por el que circulan día y noche, todos los días del año, 562 vagones, cada uno con capacidad para transportar entre 96 y 110 toneladas de carbón (Ver Figura 1). El ferrocarril dividió en dos el territorio ancestral indígena y afectó las dinámicas ambientales, sociales y productivas en la región (CGR, 2012) no sólo por su configuración espacial sino por los usos y las prácticas que genera; por ejemplo, la vigilancia del ferrocarril por parte del ejército a todo lo largo del trayecto ha implicado una militarización de hecho y permanente. El conjunto residencial y el ferrocarril ilustran las principales características de este tipo de espacios: separación de los entornos en los que se insertan, despliegue de formas alternativas de soberanía, edificación de infraestructura que permite su integración a la economía global a la vez que permite elevados niveles de autosuficiencia con respecto en los contextos local y regional, índices diferenciados de bienestar y acumulación económica, reproducción a escalas locales y regionales de la tensión centro-periferia, expansión permanente en función de las necesidades extractivas. Serje enmarca este tipo de espacios bajo la categoría de "sistema y política de enclave" (2011 [2005]), algunos de cuyos antecedentes ya hemos referido en la anterior parte. En síntesis, en La Guajira el neoliberalismo se presentó en sus formas recurrentes: desregulación del mercado, el despliegue de nuevas formas de producción como el extractivismo, la privatización medioambiental y una incidencia cada vez mayor de las empresas privadas 
en lo público (Salamanca Villamizar, Astudillo Pizarro y Fedele, 2016: 36). En términos espaciales, la cuestión se expresó en una desigualdad creciente en las formas en que se distribuyen espacialmente costos y beneficios, en la expansión de procesos de desposesión territorial, en la implantación de una geografía del enclave, y en el aumento de conflictos por los territorios y los recursos (ibid., 37).

En el marco de sendas transformaciones en los marcos jurídicos que regulaban las relaciones entre los Estados de toda la región latinoamericana y los pueblos indígenas y comunidades negras o afro, la reforma constitucional de 1991, significó la posibilidad de que a los wayúu, a los demás pueblos indígenas y a otros colectivos étnicos que habitan en Colombia, les fuera reconocido un conjunto de derechos colectivos específicos. La complejidad de este proceso nos impide desarrollar la discusión aquí, por lo que remitimos a otro trabajo (Salamanca y Tola, 2008). No obstante, en todo el país y aun con mayor intensidad en regiones como La Guajira estas medidas enfrentaron un sinnúmero de resistencias. Sin extendernos en las más habituales formas a través de las cuáles los derechos indígenas reconocidos simplemente son negados, quiero detenerme aquí en aquellos mecanismos y dispositivos de poder a través de los cuáles los wayúu ejercen —o no- sus derechos políticos colectivos. Lejos de ser contradictorio, el reconocimiento de las identidades es coherente con la expansión de formas de producción como las extractivas y el despliegue de geografías segmentadas y de enclaves.

Figura 1. El ferrocarril de El Cerrejón

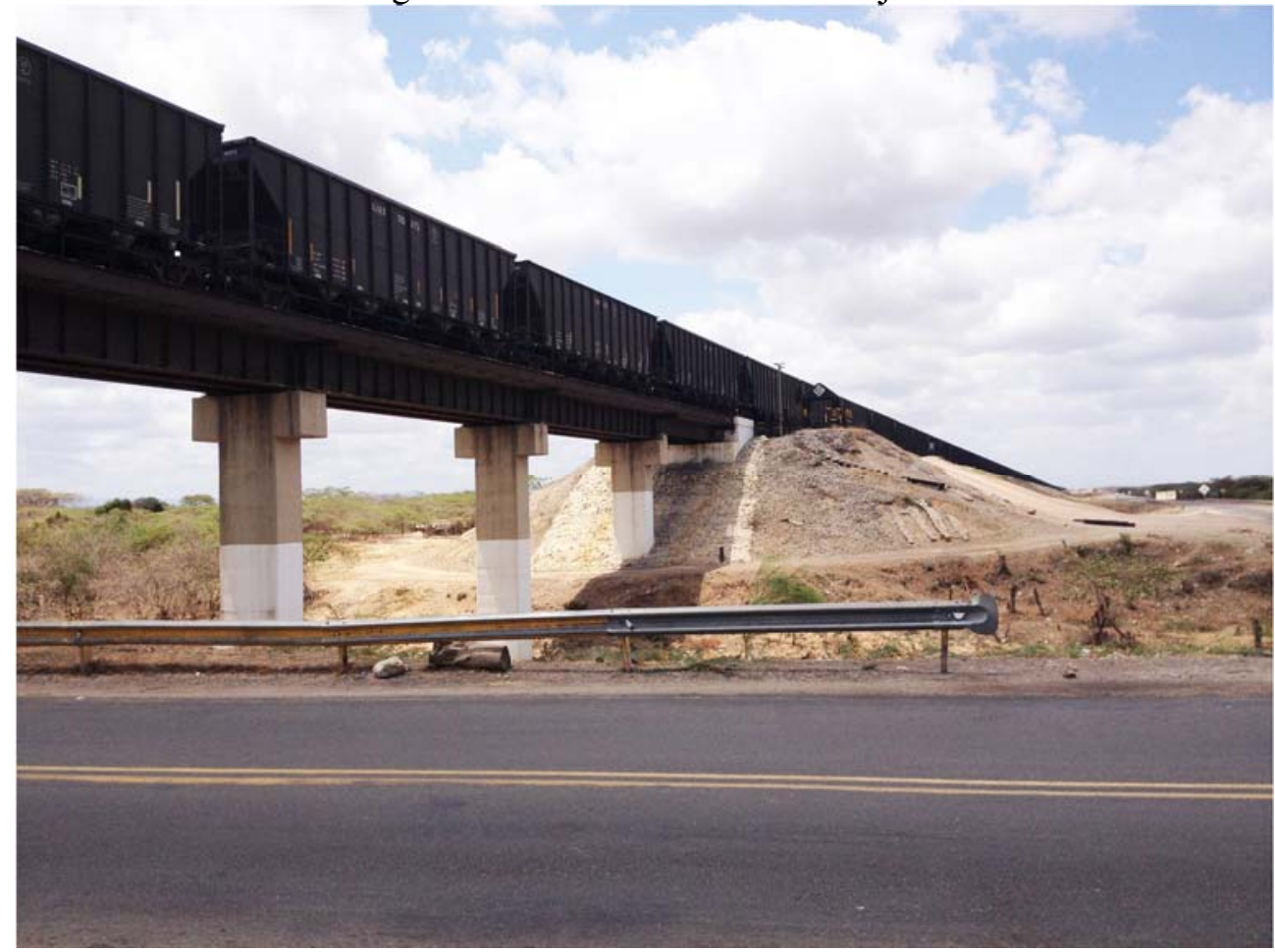

Fuente: Foto de Carlos Salamanca (Abril de 2016). 
En una compleja conjunción, el multiculturalismo y el neoliberalismo se articularon dando lugar a una serie de dispositivos políticos relacionales que constituyen campos al interior de los cuales se llevan a cabo distintos relacionamientos políticos entre las agencias del Estado y los wayúu. Estos dispositivos competen a diversas esferas de la vida social como la educación intercultural, los proyectos de salud, la producción económica, la explotación de los recursos naturales, el cuidado del medio ambiente, la vigilancia de las fronteras, el turismo y la justicia transicional. A través de mecanismos de participación, piedra angular del relacionamiento de los indígenas con los Estados, los wayúu en tanto sujetos participan en el funcionamiento y expansión de todo tipo de iniciativas. Los wayúu no fueron víctimas pasivas de esta nueva configuración y de hecho participaron y participan actualmente al interior de dichos dispositivos.

Aunque la participación de los wayúu hoy en día es casi inobjetable, y dichos dispositivos hayan adquirido mayores niveles de sofisticación bajo figuras políticojurídicas como la Consulta previa, esos relacionamientos presentan, entre otras, cuatro características. Primero, una desigualdad estructural que se explica por una participación que se produce de manera acotada y restringida a las lógicas de cada uno de los dispositivos propuestos, por el uso de lenguajes técnicos y protocolos estandarizados (Carmona Castillo, 2013). Segundo, la segmentación en campos de relacionamiento escindidos; refiriéndose a los sistemas de salud en La Guajira, Puerta Silva (2010: 41), afirma que la geopolítica y la política neoliberal segmentan las poblaciones en relación con las políticas sociales, excluyen sectores, refuerzan las desigualdades y debilitan la función estatal. Asimismo, afirma la autora, se enfocan en el individuo, desarrollan un consumidor de servicios, generan una dinámica de mercado, limitan la participación y la movilización colectiva. Tercero, una fragmentación del sistema político en una red compuesta por aproximadamente 230 autoridades comunitarias, veintiséis resguardos, quince gobiernos municipales y otras entidades territoriales (departamentos y distritos) con diferentes extensiones y número de habitantes, que se superponen política, presupuestaria y territorialmente de maneras variadas (Duarte, sf). Cuarto, una difícil operatividad en lo económico, lo político y lo jurídico que se deriva de las dificultades de articulación, planificación y articulación tanto al interior de la red de autoridades comunitarias como entre éstas y las entidades gubernamentales departamentales y nacionales como la Gobernación, los Ministerios nacionales, el Departamento Nacional de Planeación y otras agencias y oficinas del Estado.

En síntesis, el "reconocimiento de los derechos indígenas" en La Guajira en la práctica, se enfrentó por una parte, a intereses políticos, económicos y ambientales (CNMH, 2013: 131). Por otra, a unos mecanismos de relacionamiento político caracterizados por una desigualdad estructural que se reproduce al interior de los mecanismos de participación, la segmentación en campos de relacionamiento escindidos, la fragmentación de sus sistemas políticos y una difícil operatividad en lo económico, lo político y lo jurídico.

Otro elemento que contribuyó al debilitamiento de las posibilidades de los wayúu de resolver sus condiciones de existencia tiene que ver con la militarización que desde Colombia y desde Venezuela se vino produciendo en los últimos años a través de la creación de batallones, zonas de excepción y cierres de frontera que además de (re)militarizar sus territorios, dificultaron a los wayúu el acceso a artículos de primera necesidad así como sus actividades económicas. En una región en la 
que el contrabando ha sido no la excepción sino la regla, las limitaciones a dichas economías ocultas sin la implementación de otras alternativas económicas que las remplacen ataca directamente a las economías familiares de la región asociadas o no al contrabando. En síntesis, el proceso de empobrecimiento y exclusión de los wayúu fue paralelo y articulado a la expansión minera, e inversamente proporcional a su "reconocimiento cultural" y a la visibilidad de sus tradiciones, vestidos, mitos, bailes tradicionales y mochilas en la esfera pública.

Por último, es preciso subrayar que la soberanía territorial en contextos como los de la frontera colombo-venezolana ha sido reconocida como una "ficción espacio-legal", al decir de Salter (2008: 363). No obstante, tanto la idea de la porosidad de la frontera, como la de la ficción de la soberanía se vieron cuestionadas frente a la expulsión compulsiva de más de veinte mil colombianos en el contexto de la lucha contra el contrabando del lado venezolano en el 2014 y 2015, y a la afluencia de venezolanos a Colombia en el 2016 en busca de alimentos en el marco de una gran escasez. En esos episodios de la guerra contra el contrabando y de la procura por el alimento, las performances de la soberanía y otras políticas de frontera en el contexto de los procesos de inmigración, refugio y expulsión, adquirieron una dramática materialidad.

\subsection{La sed en La Guajira contemporánea: ¿una paradoja?}

El 19 de julio del 2014, un reportaje dio a la luz la grave situación alimentaria en La Guajira y en particular de los wayúu (Revista Semana, 2014a), y a partir de entonces, numerosos artículos (Revista Semana, 2014b, 2015a, 2015b, 2015c, 2015d) y otros materiales entre los que sobresale el documental El río que se robaron (Guillén, 2015) mantuvieron el tema en la agenda pública. A pesar de lo sorpresivo de la noticia, el problema no era nuevo; ya en el 2009 los indicadores del Departamento indicaban niveles de pobreza del 67\% y de pobreza extrema del 32.4\% (Gobernación de La Guajira-PNUD, 2011: 9; Defensoría del Pueblo de Colombia, 2014). De acuerdo a las estadísticas oficiales, entre el 2008 y el 2013 murieron 4.151 niños: 278 por falta de comida, 2.671 por enfermedades que pudieron haberse tratado y 1.202 que no alcanzaron a nacer. Otras fuentes reportaban alrededor de 37.000 niños en situación de desnutrición (El Espectador, 2014) . $^{8}$

El debate nacional acerca de las causas de la desnutrición rondaba en torno a las altas sumas de dinero enviadas a la región por el Gobierno Nacional y aquellas transferidas por las explotaciones mineras en concepto de distintas variables impositivas. Diversas voces entre las que se cuentan entidades del Gobierno Nacional como la Contraloría y la Fiscalía, las empresas mineras y las mismas organizaciones wayúu señalaron que las prácticas de corrupción y clientelismo impedían la correcta utilización de los fondos públicos en las obras de suministro de agua potable y las políticas de atención alimentaria y salud (Revista Semana, 2015a; El Tiempo, 2016). Prácticas que se dan a todos los niveles y que demostrarían que más que una "deformación", la corrupción es característica de la gubernamentalidad en la región. Un segundo argumento esbozado fue la drástica reducción en el régimen de

8 Éstas estadísticas son problemáticas pues se reconoce que muchas de esas muertes no son denunciadas por los familiares, en razón de la distancia de hospitales, centros de salud y oficinas del Estado. 
lluvias que ha producido un acceso cada vez más limitado al agua potable y limitado las actividades productivas de subsistencia (El Tiempo, 2015). En tercer lugar, algunos expertos intentaron explicar la dificultad de proyectos de agua potable y saneamiento dada la dispersión territorial de los conjuntos residenciales wayúu. A su vez, en entrevistas y notas de prensa, autoridades de organismos del Estado como el ICBF intentaron explicar la desnutrición de los niños con argumentos culturalistas como la "costumbre" de que los adultos se alimenten primero y después los niños, o la poca responsabilidad con que asumen la tarea de llevar oportunamente a los menores a los centros de desarrollo nutricional; sobre estas bases, subrayaron la responsabilidad de los wayúu (principalmente de los hombres) en casos de desnutrición que eran judicializados bajo la figura de los delitos de inasistencia alimentaria, maltrato físico y abandono (Sáchica Moreno, 2015; CIDH, 2015: punto 10.C).

\section{Interrogantes en torno a lo transversal y lo común}

Durante varios meses, los medios de comunicación registraron con dramatismo las dificultades cotidianas de los wayúu. El gobierno implementó la realización de obras públicas, la atención hospitalaria y envío de agua intentando sortear la intermediación de las estructuras políticas locales. Iglesias, organizaciones sociales y fundaciones de todo el país promovieron colectas de agua y alimentos y organizaron "operativos y brigadas aéreas", "brigadas" y "misiones" a la región (El Tiempo, 2014). Organizaciones multilaterales como el PNUD y UNICEF también implementaron acciones, algunas de ellas en asocio con empresas transnacionales. El Cerrejón reimpulsó un programa de acceso al agua en casi 150 comunidades, principalmente, a través de carro-tanques y la construcción de pozos, molinos de agua y fuentes de agua. Otras iniciativas se han dirigido a mejoramiento del sistema de salud, intentando "fortalecer las capacidades de los usuarios" con una "participación informada y eficiente" (Puerta Silva y Dover, 2012).

Al mismo tiempo, líderes y organizaciones wayúu, académicos y periodistas propusieron otras perspectivas, subrayando, por ejemplo, el hecho de que El Cerrejón gasta cada día 17 millones de litros de agua en su operación (Márquez Valderrama, 2014; Roa Avendaño y Navas, 2014). En esta misma dirección, en el año 2014 dos organismos de control se refirieron a las inversiones y proyectos realizados para asegurar el acceso al agua potable en La Guajira (Defensoría del Pueblo de Colombia, 2014; Procuraduría General de la Nación, 2014; CGR, 2013, sf) y en particular, a la represa de El Cercado construida en el 2010 en el río Ranchería con los fondos obtenidos por el Departamento de La Guajira de la venta de CARBOCOL a las empresas transnacionales de El Cerrejón ${ }^{9}$. La represa estaba destinada a una mejor utilización del agua del río y la construcción de un sistema de riego; no obstante, durante la construcción de las obras, los habitantes de la zonas adyacentes a la represa denunciaban problemas sanitarios como el aumento de casos de dengue y chikunguña, inundación de tierras, destrucción de fauna y flora, y disminución del cauce del río Ranchería; una vez construidas, y por dinámicas

9 Construida por el Gobierno Nacional a través del INCODER (Instituto Colombiano de Desarrollo Rural) y la Gobernación de la Guajira. La obra fue realizada entre el 2007 y el 2010 con una inversión aproximada de 650 mil millones de pesos. 
que han sido analizadas por Carmona Castillo (2013) fueron los grandes propietarios de tierras quienes se vieron favorecidos por sobre los indígenas y los campesinos pobres. La represa también se proponía el abastecimiento de los acueductos municipales de las poblaciones de Albania, Barrancas, Fonseca, Hatonuevo, Maicao, Manaure y Uribia, muchas de ellas de población mayoritariamente wayúu ${ }^{10}$. Aunque la represa fue construida, ni el sistema de riego ni el abastecimiento de agua a dichos municipios fue realizada y estas obras fueron definidas como una segunda etapa que a la fecha no tienen presupuesto ni un plan de realización inmediato (Defensoría del Pueblo de Colombia, 2014; El Espectador, 2015a; Procuraduría General de la Nación, 2014).

La lógica extractiva que privilegia la sobre-explotación de los recursos naturales en detrimento incluso de las condiciones de vida de los habitantes de las regiones en las que se encuentran emergió en dos episodios. El primero, el proyecto hecho público por El Cerrejón en el año 2011 de traslado del río Ranchería en el marco de la expansión de la explotación (al que no nos referiremos aquí por haberlo hecho en otra parte; al respecto, ver Acosta Gamboa, 2013). El segundo, un nuevo proyecto anunciado en marzo de 2015: el desvío de 3,6 km del arroyo Bruno, un afluente del río Ranchería, con el fin de expandir los límites actuales de la mina (El Espectador, 2015b). En ambos casos se presentaron varias movilizaciones compuestas por diferentes sectores de la población de la región, entre ellos los wayúu, que se organizaron en coaliciones como el Comité Cívico por la Dignidad de La Guajira. Sus discursos vinculaban la crisis humanitaria en La Guajira con la implantación de un modelo extractivo, declaraban que la escasez de agua más que a fenómenos naturales, responde a la asimetría en su uso, y esbozaban novedosos posicionamientos políticos centrados en el territorio, los recursos, lo común.

El 9 de febrero de 2015 el líder wayúu Javier Rojas Uriana y su abogada Carolina Sáchica Romero solicitaron a la Corte Interamericana de Derechos Humanos, medidas cautelares para proteger la vida y la integridad personal de los miembros de las comunidades de Uribia, Manaure, Riohacha y Maicao del pueblo wayúu en vista de la falta de acceso al agua potable y el estado de desnutrición que el mismo causaría a los miembros de la comunidad ${ }^{11}$. Los demandantes argumentaban que esta situación había causado la muerte de 4770 niños y niñas durante los últimos ocho años (CIDH, 2015) y exigían primero que se permitiera "el paso del río Ranchería por su caudal natural", y que se realizara "un estudio costo-beneficio que evalúe la viabilidad de los proyectos de carbón a cielo abierto y de gran escala existentes en la Guajira" (CIDH, 2015, punto 1).

El 11 de diciembre del 2015 la Comisión dictó medidas cautelares obligando al Estado colombiano a preservar la vida y la integridad personal de los afectados, garantizando la disponibilidad, accesibilidad y calidad de los servicios de salud con un enfoque integral y culturalmente adecuado, proveer acceso al agua potable y salubre de manera sostenible y suficiente y disponer alimentos en cantidad y calidad

10 En informes posteriores, la Contraloría General de la República de Colombia encontró graves irregularidades. Entre otros, responsabilizaba a la Gobernación de la Guajira de "incumplir con la construcción y puesta en marcha del Sistema Integral de Acueducto y Abastecimiento de agua potable" en un corregimiento del área rural de Riohacha. Cf. CGR (2016a, 2016b).

11 Similares acciones de judicialización de casos relacionados con el hambre y la desnutrición han sido emprendidas en diferentes escenarios judiciales en países como Guatemala (2012) y Argentina (2010). 
suficiente para satisfacer las necesidades alimentarias con pertinencia cultural. Sobre el supuesto impacto que estaría generando la implementación de proyectos extractivos, en relación con el río Ranchería y su supuesta incidencia, la Comisión afirmó no tener "los suficientes elementos", para evaluar las consecuencias específicas que las comunidades del pueblo wayúu "estarían enfrentando en sus derechos a la vida, integridad personal y salud y cuáles serían las medidas que el Estado no estaría implementando para atender la alegada situación" (CIDH, 2015, punto 23).

Mientras tanto y como consecuencia de las acciones adelantadas, Rojas Uriana y su familia habrían recibido amenazas de muerte por parte de "grupos de mafias en cabeza de funcionarios de las administraciones locales y departamental de la Guajira" (CIDH, 2015, punto 3.F).

\section{Comentarios finales}

Un niño muere, sin agua, sin alimentos; el registro de esa muerte muchas veces es inexistente. Cuando existe, ese niño sin nombre, es un número, un dato estadístico. Ese niño que muere no es un semejante, es un niño alterizado bajo la figura del indígena. Pero cuando muere ese niño tampoco es un sujeto, ni un niño, ni un wayúu, es una vida fisiológica cuya dimensión política queda anulada por estar situada en territorios ajenos a aquellos de las soberanías. Al margen de unas soberanías nacionales, inacabadas o inexistentes, cuyos dispositivos de poder son insuficientes para garantizar la vida. Por fuera de soberanías identitarias y culturalistas, en cuyo marco el proyecto de vida de los wayúu, sustentado en la autodeterminación, en el respeto de sus derechos territoriales y en la garantía al acceso a los recursos, se enfrenta a una paradójica evidencia: las técnicas biopolíticas del capitalismo tardío encuentran en el multiculturalismo un elemento fundamental para su expansión.

Centrándonos en las formas en que las nociones de excepción y excepcionalidad han operado en la política, la economía, la violencia y la cultura en las zonas de frontera podemos dar cuenta más fehaciente de cómo se practican la ciudadanía, la soberanía y las formas de la gubernamentalidad. Los dispositivos de la excepción y de la excepcionalidad reconfiguran permanentemente las alteridades y las identidades en función de una serie de matrices (soberanía, seguridad, productividad) en las que la vida, las garantías de la vida, se ven desplazadas de su centro. Así, en tanto otros, esos semejantes se enfrentan permanentemente a situaciones y territorios de excepción frente a los cuales su vida no puede ser garantizada.

Las zonas de frontera están en los intersticios de diversas soberanías que producen un territorio segmentado, segregado y desigual en donde se despliegan múltiples actores que establecen diversos tipos de gobernanza en áreas, zonas y enclaves, cercados por fronteras visibles o invisibles, demarcados por legislaciones específicas, al interior de las cuales operan distintas formas de gobernabilidad, se accede de maneras distintas a los recursos naturales, y la seguridad. En el intersticio de múltiples soberanías inacabadas, en aquellos umbrales de indeterminación, para muchos semejantes-otros, la nuda muerte se yergue como la continuidad de la nuda vida.

La política de las identidades en La Guajira establece horizontes segmentados de acción política que habilitan posicionamientos en los que el sujeto se ve escindido en sus múltiples representaciones. El análisis de las formas específicas en que 
estados y espacios de excepción se materializan permite evidenciar que los procesos de subjetivación y desubjetivación implicados en el despliegue de los dispositivos políticos se yerguen sobre un territorio en el que las posibilidades de la vida misma están en entredicho. Un posicionamiento post-identitario, que se sitúe simultánea y transversalmente en un lugar de acción y elocución por fuera de los dispositivos políticos relacionales tal como aparecen hoy en día en los que ni la nuda vida ni la nuda muerte sean el resultado imprevisto y seguro de las excepcionalidades contradictorias.

Sustrayéndose a las limitaciones que establecen los dispositivos políticos relacionales en los que participan, los wayúu han venido denunciando la sustracción de sus recursos naturales por la complicidad de las empresas y el Estado a través de una gran diversidad de prácticas comunicativas que no han sido objeto de análisis aquí pero a las que nos referimos en otros trabajos (Salamanca Villamizar, 2015, 2016).

En dichas ocasiones, las alianzas con otros actores como sindicatos, docentes, habitantes urbanos, campesinos, comunidades negras y organizaciones no indígenas han dado lugar a consignas que ponen en relieve aquello que es compartido y transversal. Tal vez allí se encuentren algunas pistas para sustraerse a aquellos dispositivos de poder construidos sobre las separaciones coloniales y postcoloniales de los existentes y de los territorios que habitan.

\section{Bibliografía}

Acosta Gamboa, Grace (2013) Iiwo’uyaa, la primavera wayúu. Tesis de grado, Facultad de Comunicación y Lenguaje, Pontificia Universidad Javeriana, Bogotá.

Agamben, Giorgio (2010 [2003]) Estado de excepción. Homo Sacer, II,1. Buenos Aires: Adriana Hidalgo Editora.

Agier, Michel (2015) Zonas de frontera. La antropología frente a la trampa identitaria. Rosario: UNR Editora.

Agnew, John, y Oslender, Ulrich (2010) “Territorialidades superpuestas, soberanía en disputa: lecciones empíricas desde América Latina”. Tabula Rasa, núm. 13, 191-213.

Anderson, Benedict (1993 [1983]) Comunidades imaginadas. Reflexiones sobre el origen y la difusión del nacionalismo. México: Fondo de Cultura Económica.

Aparicio, Juan Ricardo (2012) Rumores, residuos y Estado en "la mejor esquina de Sudamérica”. Bogotá: Ediciones Uniandes.

Arendt, Hannah (2006) Sobre la violencia. Madrid: Alianza Editorial.

Arteaga, Nelson (2009) "The Merida Initiative: Security-Surveillance Harmonization in Latin America". European Review of Latin American and Caribbean Studies, núm. 87, 103-110.

Asad, Talal (2008) “¿Dónde están los márgenes del Estado?”. Cuadernos de Antropología Social, núm. 27, 53-62.

Bhabha, Homi (1994) The Location of culture. Londres y Nueva York: Routledge.

Carmona Castillo, Susana (2013) Conflictos en un megaproyecto de desarrollo regional, el caso del proyecto río Ranchería en La Guajira, Colombia. Tesis de Maestría en Estudios Socio-espaciales, Universidad de Antioquia, INER, Medellín. 
Comaroff, Jean, y Comaroff, John (2003) "Ethnography on an awkward scale Postcolonial anthropology and the violence of abstraction". Ethnography, vol. 4, núm. 2, 147-179.

Das, Veena, y Poole, Deborah (2008) "El estado y sus márgenes. Etnografías Comparadas". Cuadernos de Antropología Social, núm. 27, 19-52.

Duarte, Carlos (sf) "Los Macromodelos de la Gobernanza Indígena colombiana: un análisis socioespacial a los conflictos territoriales del multiculturalismo operativo colombiano". Revista Maguaré, en prensa.

Foster, Robert (2002) "Bargains with Modernity in Papua New Guinea and Elsewhere". Anthropological Theory, vol. 2, núm. 2, 233-51.

Foucault, Michel (2004 [2001]) Seguridad, territorio, población. Buenos Aires: FCE.

Foucault, Michel (2000 [1997]) Defender la sociedad. Buenos Aires: FCE.

Foucault, Michel (1984 [1967]) “Of Other Spaces, Heterotopias". Architecture, Mouvement, Continuité, núm. 5, 46-49.

García, Mauricio, y Uprimny, Rodrigo (2006) "El control judicial de los estados de excepción en Colombia”, en R. Uprimny, C. Rodríguez y M. García (eds.) ¿Justicia para todos? Sistema judicial, derechos sociales y democracia en Colombia. Bogotá: Norma, 531-569.

García Hierro, Pedro, y Jaramillo, Pedro (2008) Colombia: El caso del Naya. Desarraigo Territorial de poblaciones indígenas, campesinas y afrodescendientes como un objetivo de guerra. Bogotá: IWGIA.

García Villegas, Mauricio (2008) “Un país de estados de excepción”, El Espectador, 11 de octubre. [En línea. URL: $<$ http://www.elespectador.com/impreso/politica/articuloimpreso43317-un-pais-deestados-de-excepcion>. Consultado el 12 de enero de 2016].

González, Fernán; Bolívar, Ingrid, y Vázquez, Teófilo (2003) Violencia política en Colombia. De la nación fragmentada a la construcción del Estado. Bogotá: CINEP.

González Jacome, Jorge (2007) "Exceptionalism as a colonial tool in modern international law”, International Law: Revista Colombiana de Derecho Internacional 10, 15-42.

Gregory, Dereck (2004) The colonial present. Maiden: Blackwell.

Gregory, Dereck (2006) "The Black Flag: Guantánamo Bay and the Space of Exception". Geografiska Annaler. Series B, Human Geography, vol. 88, núm. 4, 405-427.

Gupta, Akhil, y Ferguson, James (2008 [1997]) "Más allá de la «cultura». Espacio, identidad y las políticas de la diferencia". Antípoda, núm. 7, 233-256.

Hannah, Matthew (2008) "Spaces of Exception and Unexceptionability”, en D. Cowen y E. Gilbert (eds.) War, Citizenship, Territory. Londres y Nueva York: Routledge, Taylor \& Francis, 57-73.

Hardt Michael, y Antonio Negri (2004) Multitud. Guerra y democracia en la era del Imperio. México: Debate.

Jameson, Fredric (2003) “The end of temporality”. Critical Inquiry, núm. 29, 695-718.

Lal, Vinay (2005) "The concentration camp and development: the pasts and future of genocide". Patterns of Prejudice, vol. 39, núm. 2, 220-243.

Madariaga, Patricia (2006) Matan y Matan y uno sigue ahí: control paramilitar y vida cotidiana en un pueblo de Urabá. Bogotá: Universidad de los Andes.

Malkki, Liisa (1995) Purity and Exile: Violence, Memory, and National Cosmology among Hutu Refugees in Tanzania. Chicago: Chicago University Press.

Márquez Valderrama, Javier (2104) "Entre sequías y privatizaciones” Penca de Sábila, 20 de septiembre. 
Mason, Ann (2005) "Constructing Authority Alternatives on the Periphery: Vignettes from Colombia”. International Political Science Review, vol. 26, núm. 1, 37-54.

Mbembe, Achille (2011) Necropolítica. Seguido de sobre el gobierno privado indirecto. Madrid: Melusina.

Morton, Stephen (2012) "Fictions of sedition and the framing of Indian revolutionaries in colonial India”. The Journal of Commonwealth Literature, vol. 47, núm. 2, 175-189.

Njoh, Ambe J. (2008) "The segregated city in British and French colonial Africa". Race Class, núm.49, 487-495.

Ochoa Sierra, María (2011) Horror sin nombre. Impacto de la entrada de los paramilitares en territorio wayú. Bogotá: Universidad de los Andes.

Palacios, Marco (1995) Entre la legitimidad y la violencia. Bogotá: Grupo Editorial Norma.

Parekh, Bhikhu (1995) "Ethnocentricity of the nationalist discourse". Nations and Nationalism, vol. 1, núm. 1, 25-52.

Pécaut, Daniel (1987) Orden y violencia: Colombia 1930-1954. Bogotá: CREC-Siglo XXI.

Polo Acuña, José Trinidad (2000) “Contrabando y pacificación indígena en una frontera del Caribe colombiano: La Guajira (1750-1800)”. Aguaita, Revista del Caribe colombiano, núm. 3, 41-62.

Polo Acuña, José Trinidad (2012) Indígenas, poderes y mediaciones en La Guajira en la transición de la Colonia a la República (1750-1850). Bogotá: Universidad de los Andes.

Puerta Silva, Claudia (2010) "Pueblos indígenas y sistemas de salud: participación local en el contexto de las reformas neoliberales y multiculturales en Colombia". Textos y Sentidos, núm. 1, 39-61.

Puerta Silva, Claudia (2014) "Las múltiples alteridades en el Desarrollo: más allá de la interculturalidad étnica”. Revista de Antropología Social, núm. 23, 55-72.

Puerta Silva, Claudia, y Dover, Robert (2008) “¿Tierras baldías, territorios de nadie? Geopolítica de un proyecto minero en La Guajira colombiana", en E. Piazzini, y V. Montoya (eds.) Geopolíticas: Espacios de Poder y Poder se los Espacios. Colombia: La Carreta Editores, 31-50.

Radcliffe, Sarah (2007) "Latin American Indigenous Geographies of Fear: Living in the Shadow of Racism, Lack of Development, and Antiterror Measures". Annals of the Association of American Geographers, vol. 97, núm. 2, 385-397.

Reid-Henry, Simon (2007) "Exceptional Sovereignty? Guantánamo Bay and the ReColonial Present". Antipode, vol. 39, núm. 4, 627-648.

Roa Avendaño, Tatiana, y Navas, Luisa María (coords.) (2014) Extractivismo. Conflictos y resistencias. Bogotá: Censat Agua Viva - Amigos de la Tierra Colombia.

Sáchica Moreno, Carolina (2015) "El único "estado" que conocen los wayúu es el de abandono". Revista Semana, 23 de diciembre 2015 [URL: $<$ http://www.semana.com/opinion/articulo/el-unico-estado-que-conocen-los-wayúu-erael-de-abandono/454671-3>. Consultado el 1 de febrero de 2016].

Safford, Frank, y Palacios, Marco (2002) Colombia: Fragmented Land, Divided Society. Oxford: Oxford University Press.

Salamanca Villamizar, Carlos (2015) "Terrores guajiros. Lecturas transversales entre las políticas de la identidad, la violencia masiva y la economía transnacional". Revista de Antropología Social, núm. 24, 287-315 [En línea. URL: $<$ https://revistas.ucm.es/index.php/RASO $>$. Consultado el 13 de febrero de 2016]. 
Salamanca Villamizar, Carlos, y Astudillo Pizarro, Francisco (2016) “Justicia(s) espacial(es) y tensiones socio-ambientales. Desafíos y posibilidades para la etnografía a un problema transdisciplinario". Etnografías Contemporáneas, en prensa.

Salamanca Villamizar, Carlos; Astudillo Pizarro, Francisco, y Fedele, Javier (2016) "Trayectorias de la(s) justicia(s) espacial(es) en América Latina. Un estudio introductorio", en B. Bret et al. (comps.) Justicia e injusticias espaciales. Rosario: UNR Editora, 1166.

Salamanca, Carlos, y Tola, Florencia (2008) "Pueblos Indígenas", en H. Biagini y A. Roig (eds.). Diccionario del pensamiento alternativo. Buenos Aires: Biblos, 436-438.

Salter, Mark (2008) "When the exception becomes the rule: borders, sovereignty, and citizenship". Citizenship Studies, vol. 12, núm. 4, 365-380.

Sassen, Saskia (2010 [2006]) Territorio, autoridad y derechos. De los ensamblajes medievales a los ensamblajes globales. Madrid: Katz.

Serje, Margarita (2011 [2005]) El revés de la nación. Territorios salvajes, fronteras y tierra de nadie. Bogotá: Universidad de Los Andes.

Shenhav, Yehouda (2012) "Imperialism, Exceptionalism and the Contemporary World", en M. Svirsky y S. Bignall (eds.) Agamben and Colonialism. Oxford: Oxford University Press, 17-31.

Soja, Edward (1996) Thirdspace: Journeys to Los Angeles and Other Real-and Imagined Places. Oxford: Blackwell.

Svirsky, Marcelo, y Bignall, Simone (eds.) (2012) Agamben and Colonialism. Edimburgo: Edinburgh University Press.

Stanard, M. G. (2009) "Interwar pro-Empire Propaganda and European Colonial Culture: Toward a Comparative Research Agenda". Journal of Contemporary History, vol. 44, núm. 1, 27-48.

Steiner, Claudia (2000) Imaginación y poder. El encuentro del interior con la costa en Urabá, 1900-1960. Medellín: Editorial Universidad de Antioquia.

Uribe de Hincapié, María Teresa (1999) "Las soberanías en disputa: conflicto de identidades o de derechos?”. Estudios Políticos, núm. 15, 23-45.

Uribe de Hincapié, María Teresa (2001) Nación, ciudadano, soberano. Medellín: Corporación Región.

Urrea, Danilo, y Rodríguez Maldonado, Tatiana (2014) “Gran minería y conflicto. Una perspectiva socioambiental del modelo de desarrollo en Colombia”, en T. Roa Avendaño y L. M. Navas (coords.) Extractivismo. Conflictos y resistencias. Bogotá: CENSAT Agua Viva - Amigos de la Tierra Colombia, 73-106.

Villa, William (2004) Violencia política contra los pueblos indígenas en Colombia. 19742004. Santafé de Bogotá: CECOIN-OIA- IWGIA.

Warf, Barney, y Arias, Santa (eds.) (2014) The Spatial Turn: Interdisciplinary Perspectives. Nueva York: Routledge.

\section{Notas de prensa}

El Espectador (2014) "Expertos de la U. Nacional alertan sobre desnutrición en La Guajira", 29 de abril de 2014 [URL: $<$ http://www.elespectador.com/noticias/nacional/expertos-de-u-nacional-alertan-sobredesnutricion-guaji-articulo-489506>. Consultado el 1 de febrero de 2016]. 
El Espectador (2015a) "Indígenas wayúu están sin agua por la represa El Cercado", 13 de julio de 2015 [URL: <http://www.elespectador.com/noticias/nacional/indigenas-wayúuestan-sin-agua-represa-el-cercado-video-572271>. Consultado el 1 de febrero de 2016].

El Espectador (2015b) "El arroyo que se le atravesó al Cerrejón", 7 de marzo de 2015 [URL: $\quad<$ http://www.elespectador.com/noticias/medio-ambiente/el-arroyo-se-leatraveso-al-cerrejon-articulo-548145>. Consultado el 1 de febrero de 2016].

El Tiempo (2014) "Una patrulla aérea que salva vidas en La Guajira", 22 de septiembre de 2014 [URL: http://www.eltiempo.com/colombia/otras-ciudades/brigada-medica-en-laguajira/14570236>. Consultado el 1 de febrero de 2016].

El Tiempo (2015) "En La Guajira cada año llueve menos" [URL: $<$ http://www.eltiempo.com/multimedia/infografias/infografia-las-cifras-del-drama-enla-guajira/14357996>. Consultado el 1 de febrero de 2016].

El Tiempo (2016) "Wayús venden los alimentos que han sido donados", 4 de marzo de 2016 [URL: <http://www.eltiempo.com/colombia/otras-ciudades/wayus-vendenalimentos-donados/16528422>. Consultado el 1 de febrero de 2016].

Revista Semana (2014a) “¡La Guajira S.O.S.!”, 19 de julio de 2014 [URL: $<$ http://www.semana.com/nacion/articulo/los-ninos-de-la-guajira-mueren-dehambre/396290-3>. Consultado el 1 de febrero de 2016].

Revista Semana (2014b) "Alarma en la guajira por 37.000 niños desnutridos", 24 de julio de 2014 [URL: <http://www.semana.com/nacion/articulo/en-guajira-hay-37000-ninoscon-desnutricion/396788-3>. Consultado el 1 de febrero de 2016].

Revista Semana (2015a) “¿Quién se robó el agua de La Guajira?”, 4 de agosto de 2015 [URL: $\quad<$ http://www.semana.com/nacion/articulo/quien-se-robo-el-agua-de-laguajira/398006-3>. Consultado el 1 de febrero de 2016].

Revista Semana (2015b) "The Guardian: La Guajira, el corrupto lugar donde los niños mueren de sed", 19 de julio de 2015. [URL: $<$ http://www.semana.com/nacion/articulo/the-guardian-la-guajira-donde-los-ninosmueren-de-sed/431848-3>. Consultado el 1 de febrero de 2016].

Revista Semana (2015c) "En la ardiente guajira los niños mueren de hambre y sed", 23 de abril de 2015 [URL: <http://www.semana.com/nacion/articulo/guajira-ninos-aunmueren-de-hambre-sed/425074-3>. Consultado el 1 de febrero de 2016].

Revista Semana (2015d) La doble tragedia que viven los niños de La Guajira", 13 de julio de 2015. [URL: <http://www.semana.com/nacion/articulo/la-guajira-centros-deprimera-infancia-no-prestan-servicios-de-calidad/431169-3>. Consultado el 1 de febrero de 2016].

\section{Informes técnicos, comunicados oficiales y otros}

CGR - Contraloría General de la República de Colombia (sf) "Intervención CGRC en distrito de riego rio Ranchería” [En línea. URL: $<$ http://www.contraloriagen.gov.co/documents/10136/183026335/DESCRIPCI\%C3\%9 3N.pdf/070797ba-471a-4fb8-849e-b80b1530be2f $>$. Consultado el 13 de marzo de 2015].

CGR - Contraloría General de la República de Colombia (2012) Informe Especial. Bogotá: CGRC.

CGR - Contraloría General de la República de Colombia (2013) Minería en Colombia: Fundamentos para superar el modelo extractivista. Bogotá: CGRC. 
CGR - Contraloría General de la República de Colombia (2016a) "En recursos de regalías Dos hallazgos fiscales en el departamento de La Guajira por un valor de \$14.723 millones", enero de 2016. [URL: <http://www.contraloria.gov.co>. Consultado el 13 de marzo de 2015]

CGR - Contraloría General de la República de Colombia (2016b) "En auditorías realizadas el año 2015: 22 hallazgos con presunta incidencia fiscal por \$23.564 millones encontró la Contraloría al evaluar manejo de regalías en La Guajira", enero de 2016. [URL: $<$ http://www.contraloria.gov.co $>$. Consultado el 13 de marzo de 2015].

CIDH - Comisión Interamericana de Derechos Humanos (2015) Medidas cautelares No. 51/15. Niñas, niños y adolescentes de las comunidades Uribia, Manaure, Riohacha y Maicao del Pueblo Wayúu, asentados en el departamento de La Guajira, respecto de Colombia. 11 de diciembre del 2015.

CNMH - Centro Nacional de Memoria Histórica (2010) La masacre de Bahía Portete: mujeres Wayúu en la mira. Bogotá: Ediciones Semana.

CNMH - Centro Nacional de Memoria Histórica (2013) ¡Basta Ya! Colombia: Memoria de guerra y dignidad. Bogotá: CNMH.

Defensoría del Pueblo de Colombia (2014) Crisis humanitaria en La Guajira. Acción integral de la Defensoría del Pueblo en el Departamento, Bogotá: Defensoría del Pueblo.

Gobernación de La Guajira-PNUD (2011) La Guajira. Bases para una política de inclusión productiva. Bogotá: Impresol Ediciones.

Guillén, Gonzalo (2015) El río que se robaron. Documental, 53’. Producción: Alex Vernot.

ONU (2015) "Situación de los derechos humanos en Colombia". Consejo de Derechos Humanos $31^{\circ}$ período de sesiones. Informe anual del Alto Comisionado de las Naciones Unidas para los Derechos Humanos Versión Avanzada No Editada. 15 de marzo de 2016. A/HRC/31/3/Add.2.

Procuraduría General de la Nación (2014) "Represa del Río Ranchería de La Guajira no es utilizada para todos los propósitos para los que se construyó, concluye Procuraduría General de la Nación”, Boletín 594. 